\title{
INTERACTIONS OF FLUOROQUINOLONE
}

\section{ANTIBACTERIAL AGENTS WITH AQUEOUS}

\section{CHLORINE: REACTION KINETICS, MECHANISMS, AND TRANSFORMATION PATHWAYS}

Michael C. Dodd ${ }^{\dagger}$, Amisha D. Shah ${ }^{\ddagger}$, Urs von Gunten ${ }^{\dagger}$, and Ching-Hua Huang ${ }^{\ddagger *}$

${ }^{\dagger}$ Swiss Federal Institute of Aquatic Science and Technology (EAWAG)

Duebendorf, Switzerland CH-8600

* School of Civil and Environmental Engineering, Georgia Institute of Technology Atlanta, Georgia 30332

*Corresponding author phone: 404-894-7694; fax: 404-894-8266;

e-mail: ching-hua.huang@ce.gatech.edu 


\section{List of Supporting Text, Tables, and Figures}

Text S1. Procurement and sources of wastewater and drinking water samples

Text S2. Quenching of EF reactions by reduction of residual oxidant with $\mathrm{Na}_{2} \mathrm{~S}_{2} \mathrm{O}_{3}$

Text S3. Rate constant determination by competition kinetics and continuous-flow method

Text S4. Modeling $\mathrm{pH}$-dependence of $k_{f r a g}^{\prime}$

Table S1. CF/FAC reaction products detected in unquenched reaction solutions by LC/MS-ESI . Solutions contained $[\mathrm{CF}]_{0}=270 \mu \mathrm{M}$ and $[\mathrm{FAC}]_{0}=0.6$ to $1.2 \mathrm{mM}$, at $\mathrm{pH} 7$

Table S2. EF/FAC reaction products detected in quenched and unquenched reaction solutions by LC/MS$\mathrm{ESI}^{+}$. Solutions contained $[\mathrm{EF}]_{0}=280 \mu \mathrm{M}$ and $[\mathrm{FAC}]_{0}=140$ to $560 \mu \mathrm{M}$, at $\mathrm{pH} 7$

Figure S1. Apparent pseudo-first-order rate constants measured by continuous-flow method for the $\mathrm{NH}_{3} / \mathrm{HOCl}$ reaction at $22( \pm 0.2){ }^{\circ} \mathrm{C},\left[\mathrm{NH}_{3}\right]_{\mathrm{t}, 0}=2 \times 10^{-4} \mathrm{M}$, and $[\mathrm{FAC}]_{0}=10 \times 10^{-6} \mathrm{M}$

Figure S2. LC/MS-ESI ${ }^{+}$spectra for chloramine intermediates of the reaction between $\mathrm{CF}$ and FAC ( $\mathrm{pH} 7$, from unquenched reaction solutions containing $[\mathrm{CF}]_{0}=270 \mu \mathrm{M}$ and $[\mathrm{FAC}]_{0}=0.6$ to $1.2 \mathrm{mM}$ )

Figure S3. LC/MS-ESI ${ }^{+}$spectra for $\mathrm{CF}$ and identifiable products of the reactions between FAC and CF $\left(\mathrm{pH} 7\right.$, from quenched and unquenched reaction solutions containing $[\mathrm{CF}]_{0}=270 \mu \mathrm{M}$ and $[\mathrm{FAC}]_{0}=0.6$ to $1.2 \mathrm{mM})$

Figure S4. LC/MS-ESI ${ }^{+}$spectra for EF and identifiable products of the reactions between FAC and EF $\left(\mathrm{pH} 7\right.$, from quenched and unquenched reaction solutions containing $[\mathrm{EF}]_{0}=280 \mu \mathrm{M}$ and $[\mathrm{FAC}]_{0}=140$ to $560 \mu \mathrm{M})$

Figure S5. FLU and FLU-P ( $\mathrm{pH} 7$, from unquenched reaction solutions containing $[\mathrm{EF}]_{0}=280 \mu \mathrm{M}$, $[\mathrm{FLU}]_{0}=280 \mu \mathrm{M}$, and $\left.[\mathrm{FAC}]_{0}=560 \mu \mathrm{M}\right)$

Figure S6. $[\mathrm{FAC}]_{0}$-independence of pseudo-first-order rate constant, $k_{\text {frag }}^{\prime}$, for CF-Ial decay to CF-Pa1 at $25^{\circ} \mathrm{C}$ and $\mathrm{pH} 7$

Figure S7. pH-dependence of pseudo-first-order rate constant, $k_{\text {frag }}^{\prime}$, for CF-Ial decay to CF-Pa1 at 25 ${ }^{\circ} \mathrm{C},[\mathrm{CF}]_{0}=1.4 \times 10^{-6} \mathrm{M}$, and $[\mathrm{FAC}]_{0}=1.5 \times 10^{-5} \mathrm{M}$ 
Text S1. Procurement and sources of wastewater and drinking water samples. Atlanta, GA (used for experiments with $C F$ ): Secondary wastewater effluent was taken from a regional wastewater treatment plant (WWTP) after multi-stage activated sludge treatment with nutrient removal. Filter effluent was collected from a regional drinking water treatment plant (WTP). Characteristics of both samples and corresponding process trains were as previously reported (1).

Zurich, Switzerland (used for EF experiments): Secondary wastewater effluent was taken from the Kloten/Opfikon WWTP and surface water was collected from Lake Zurich (at 30-meter depth). Unmodified samples were vacuum-filtered through $0.45 \mu \mathrm{m}$ pore-size membranes upon arrival in the laboratory, and stored at $\sim 6^{\circ} \mathrm{C}$ prior to analysis and use (no later than 2 days after collection). The sample from Kloten/Opfikon was obtained from a point in that plant's treatment train just prior to discharge into the Glatt River - following activated sludge treatment with nitrification/denitrification, while the sample from Lake Zurich represents the city's raw water supply, which is quite similar in character to post-filtration waters in most U.S. drinking water treatment facilities. Neither chlorine nor other common chemical oxidants were present in the Kloten sample, as Swiss water reclamation facilities do not practice disinfection of effluent, nor were any interfering oxidants present in the Lake Zurich sample. Water quality data for these two samples are given in Table 2 (main text). $\mathrm{pH}$ was measured in the laboratory. All other water quality measurements were provided by third-party analyses according to standard methods (2).

Text S2. Quenching of EF reactions by reduction of residual oxidant with $\mathrm{Na}_{2} \mathrm{~S}_{2} \mathrm{O}_{3}$. The feasibility of using $\mathrm{Na}_{2} \mathrm{~S}_{2} \mathrm{O}_{3}$ as a reaction quenching reductant in EF/FAC kinetic experiments was evaluated as follows. Samples of unquenched reaction solutions containing FAC:EF at 10:1 ratios were injected into the Hewlett-Packard 1050 HPLC system described in the main text as soon as possible $(\sim 10 \mathrm{~s})$ after addition of FAC. Samples of the same solutions were quenched with $\mathrm{Na}_{2} \mathrm{~S}_{2} \mathrm{O}_{3}$ at the same moment the unquenched samples were introduced on to the HPLC column (at which time FAC would have been 
separated from residual substrate). Comparison of chromatograms for the unquenched samples to those of the simultaneously quenched samples showed that EF peak area in quenched solutions was no higher than in corresponding unquenched solutions, indicating the absence of any $\mathrm{Na}_{2} \mathrm{~S}_{2} \mathrm{O}_{3}$-induced back reactions that could interfere with kinetic measurements.

\section{Text S3. Rate constant determination by competition kinetics and continuous-flow method.}

Competition kinetics. The kinetic relationship between a model compound, $\mathrm{M}$, and competitor substrate, C, in competition for a sub-stoichiometric dose of FAC can be represented by equation (S1) (3),

$$
\frac{[\mathrm{P}]_{\text {absence }}}{[\mathrm{P}]_{\text {presence }}}-1=\frac{k_{\text {app }, C}^{\prime \prime}[\mathrm{C}]_{0}}{k_{\text {app }, M}^{\prime \prime}[\mathrm{M}]_{0}}
$$

where $\mathrm{P}$ represents a product of either $\mathrm{M}$ or $\mathrm{C}$ that is measured in both the presence and absence of the paired substrate, and the constants $k_{a p p, C}^{\prime \prime}$ (known) and $k_{a p p, M}^{\prime \prime}$ (unknown) represent the apparent secondorder rate constants for the competitor substrate, $\mathrm{C}$, and the model compound of interest, M. In this case, M represents the model substrate CF, while 4,6-dichlororesorcinol was selected as the competitor, C. The rate constants $k_{a p p, M}^{\prime \prime}$ were obtained from the slopes of regression lines fitted to plots of $\frac{[\mathrm{P}]_{\text {absence }}}{[\mathrm{P}]_{\text {presence }}}-1$ $\operatorname{versus} \frac{[\mathrm{C}]_{0}}{[\mathrm{M}]_{0}}$. HPLC-UV signal areas of a product generated upon reaction of 4,6-dichlororesorcinol with FAC (presumably 2,4,6-trichlororesorcinol $(4,5)$ ) were used as the corresponding measurement endpoint, $\mathrm{P}$, with respect to varying $[\mathrm{C}]_{0}$. Experiments were conducted at $\mathrm{pH}$ ranging from 4 to 11 . However, results obtained for $\mathrm{pH} 6.5$ to $\mathrm{pH} 9$ were corrupted by some unknown complication in the reaction system. As a consequence, only values obtained at $\mathrm{pH} 4,5,6,10$, and 11 were used in calculation of specific secondorder rate constants for reaction of CF with FAC (Figure 2a, Table 3 main text). The continuous-flow method (described below) was used to obtain data at intermediate $\mathrm{pH}$ values in lieu of competition kinetics results. All competition kinetics experiments were conducted at $22{ }^{\circ} \mathrm{C}$. 
Continuous-flow method. Free chlorine decay was measured under pseudo-first-order conditions with respect to $\mathrm{CF}$ (i.e., excess $\mathrm{CF}$ ), at $\mathrm{pH}$ ranging from 5 to 11 by a continuous-flow, quenched-reaction method. Substrate and oxidant solutions were continuously pumped at equal flow rates with a Harvard Apparatus (Holliston, MA) 22 multi-position syringe pump (ranging from 2.5 to $20 \mathrm{~mL} / \mathrm{min}$ ) through a mixing tee coupled to a seven-point switching valve (Kintek Corporation - Austin, TX). The switching valve directed the mixed reaction solution through one of seven PTFE loops with volumes of 16.1, 35.2, $50.9,85.2,133.6,169.6$, and $199.3 \mu \mathrm{L}$. Reaction times in these loops ranged from $28 \mathrm{~ms}$ to $2.4 \mathrm{~s}$, depending on the total system flow rate ( 5 to $40 \mathrm{~mL} / \mathrm{min})$. The effluent of each reaction loop was directed

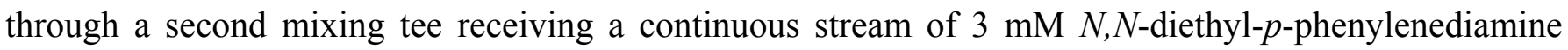
(DPD) solution (buffered at $\mathrm{pH} 6.5$ with $0.1 \mathrm{M}$ phosphate) from a third channel of the multi-position syringe pump. The effluent of the second tee was then directed through a 5-cm flow-through spectrophotometer cell, from which continuous absorbance readings were recorded at $\lambda=515 \mathrm{~nm}\left(\lambda_{\max }\right.$ for the cation radical formed in reaction of DPD with free chlorine (6)), to permit measurement of residual FAC for various reaction times. Initial substrate concentrations ranged from 15 to $100 \mu \mathrm{M}$, while initial oxidant concentrations ranged from 1.5 to $5 \mu \mathrm{M}$. Reaction rate constants were obtained from pseudo-first-order plots of $\ln ([\mathrm{FAC}])$ versus reaction time. Each $\ln ([\mathrm{FAC}])$ value was taken from timeaveraged absorbance readings obtained for each reaction loop over a minimum monitoring period of $10 \mathrm{~s}$. System calibration was performed by using the reaction between $\mathrm{NH}_{3}$ and $\mathrm{HOCl}$ as a reference. The second-order rate constant calculated for this reaction from the measured data (Figure S1) was $2.5 \times 10^{6}$ $\mathrm{M}^{-1} \mathrm{~s}^{-1}$, which agrees extremely well with the most precise reported value $\left(3.1 \times 10^{6} \mathrm{M}^{-1} \mathrm{~s}^{-1}(7)\right)$.

DPD is known to react very rapidly with free chlorine $\left(k_{a p p}^{\prime \prime} \cong 1.3 \times 10^{5} \mathrm{M}^{-1} \mathrm{~s}^{-1}\right.$ at $\left.\mathrm{pH} 6.5(8)\right)$, but only slowly with chloramines $\left(k_{a p p}^{\prime \prime}=10.2 \mathrm{M}^{-1} \mathrm{~s}^{-1}\right.$, at $\mathrm{pH} 6.5$, for the reaction between $\mathrm{NH}_{2} \mathrm{Cl}$ and DPD (6)). Interference from the secondary reactions between DPD and $\mathrm{NH}_{2} \mathrm{Cl}$ or CF-Ia1 was assumed to be negligible, as travel time from the second mixing tee to the UV cell (hence available chloramine-DPD 
reaction time) was no greater than $15 \mathrm{~s}$, and in most cases was less than $5 \mathrm{~s}$. This assumption is further supported by the accuracy of system calibration results. DPD stocks were amended with $200 \mathrm{mg} / \mathrm{L}$ of EDTA and continuously purged with nitrogen gas to retard oxidation of the DPD by dissolved oxygen. Stocks treated in this manner could be stored for up to four hours with no noticeable discoloration. All continuous-flow experiments were conducted at room temperature $\left(\mathrm{T}=22 \pm 0.2{ }^{\circ} \mathrm{C}\right)$.

Text S4. Modeling pH-dependence of $k_{f r a g}^{\prime}$. Assuming that CF-Ia1's carboxyl group exhibits approximately the same $\mathrm{p} K_{\mathrm{a}}(6.2)$ as for $\mathrm{CF}$ (because this moiety is not conjugated with the $\mathrm{N}(4)$ atom at which chlorination occurs), the magnitude of $k_{\text {frag }}^{\prime}$ can be accurately modeled according to eq (S2),

$\frac{d[C F-I a 1]}{d t}=-k_{f r a g}^{\prime}[\mathrm{CF}-\mathrm{Ia} 1]_{\mathrm{T}}=-k_{\text {frag, neutral }}^{\prime}[\mathrm{Neutral} \mathrm{CF}-\mathrm{Ia} 1]-k_{\text {frag, anion }}^{\prime}[$ Anionic CF $-\mathrm{Ia} 1]$

where $k_{\text {frag,neutral }}^{\prime}$ and $k_{\text {frag,anion }}^{\prime}$ represent the pseudo-first-order rate constants for decay of neutral and anionic CF-Ia1, respectively (Figure S7). The increase in magnitude of $k_{\text {frag }}^{\prime}$ from $\mathrm{pH} 4.6$ to 8.6 is likely due to an increase of electron density at N(1) (the electron-donating group in piperazine fragmentation) upon deprotonation of the carboxyl group (to which $\mathrm{N}(1)$ is conjugated), leading to destabilization of the $\sigma$ bond bridging the two carbon atoms $\alpha$ - and $\beta$ - to N(1). 


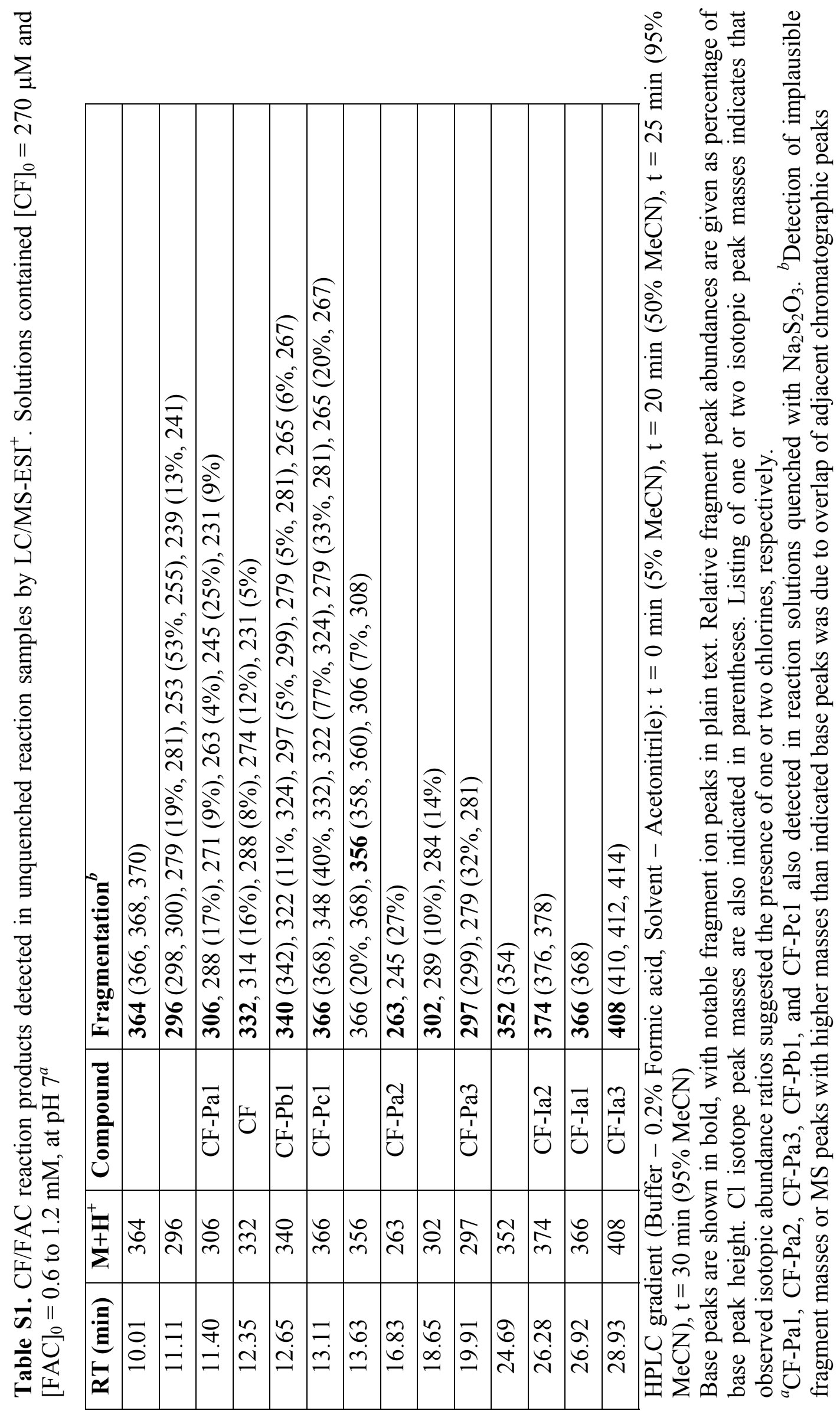




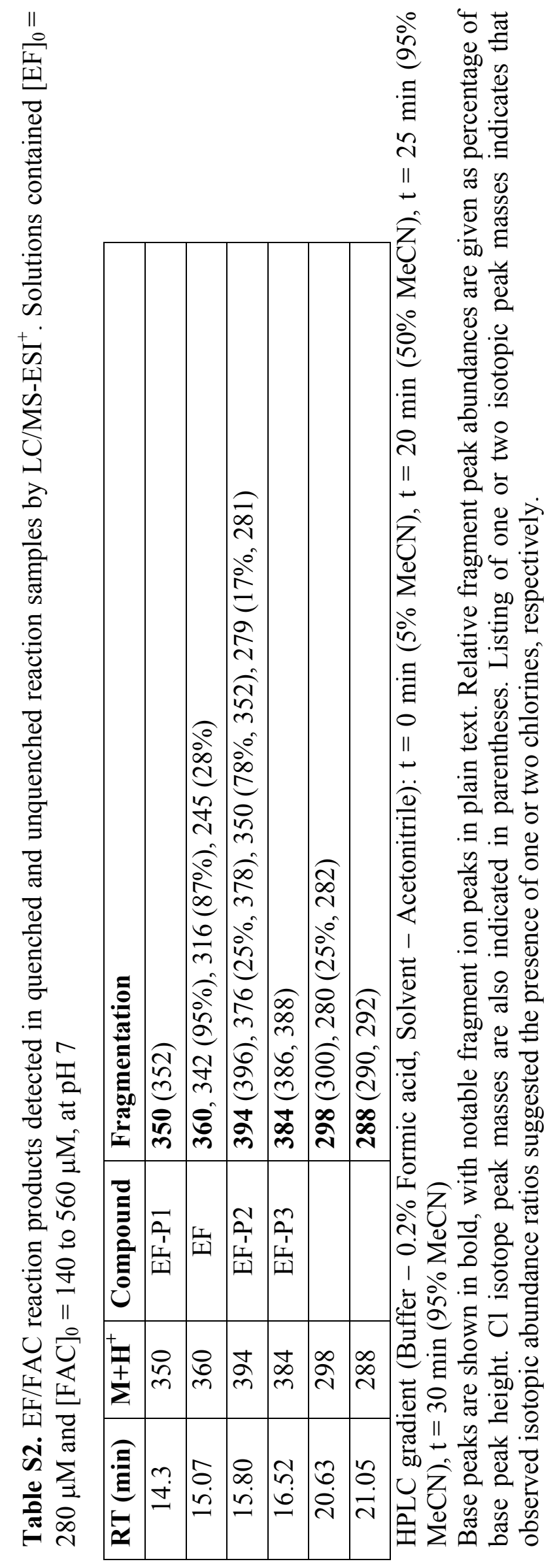




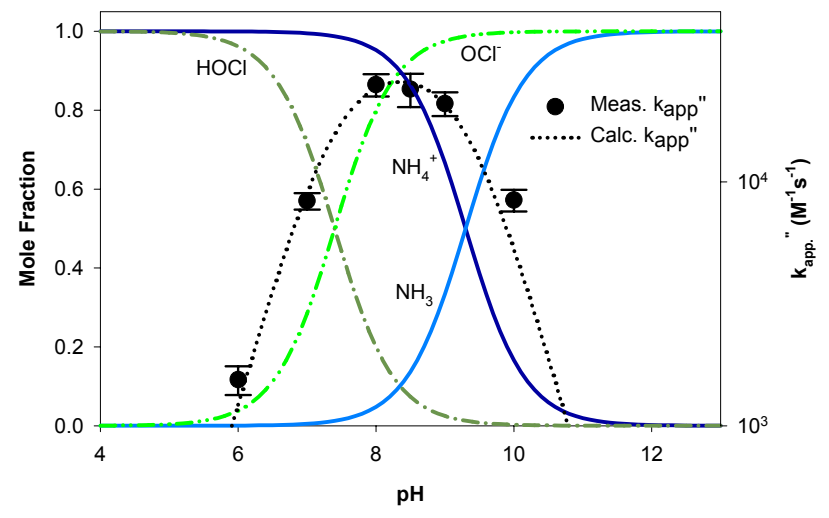

Figure S1. Apparent pseudo-first-order rate constants measured by continuous-flow method for the $\mathrm{NH}_{3} / \mathrm{HOCl}$ reaction at $22( \pm 0.2){ }^{\circ} \mathrm{C},\left[\mathrm{NH}_{3}\right]_{\mathrm{t}, 0}=2 \times 10^{-4} \mathrm{M}$, and $[\mathrm{FAC}]_{0}=10 \times 10^{-6} \mathrm{M}$

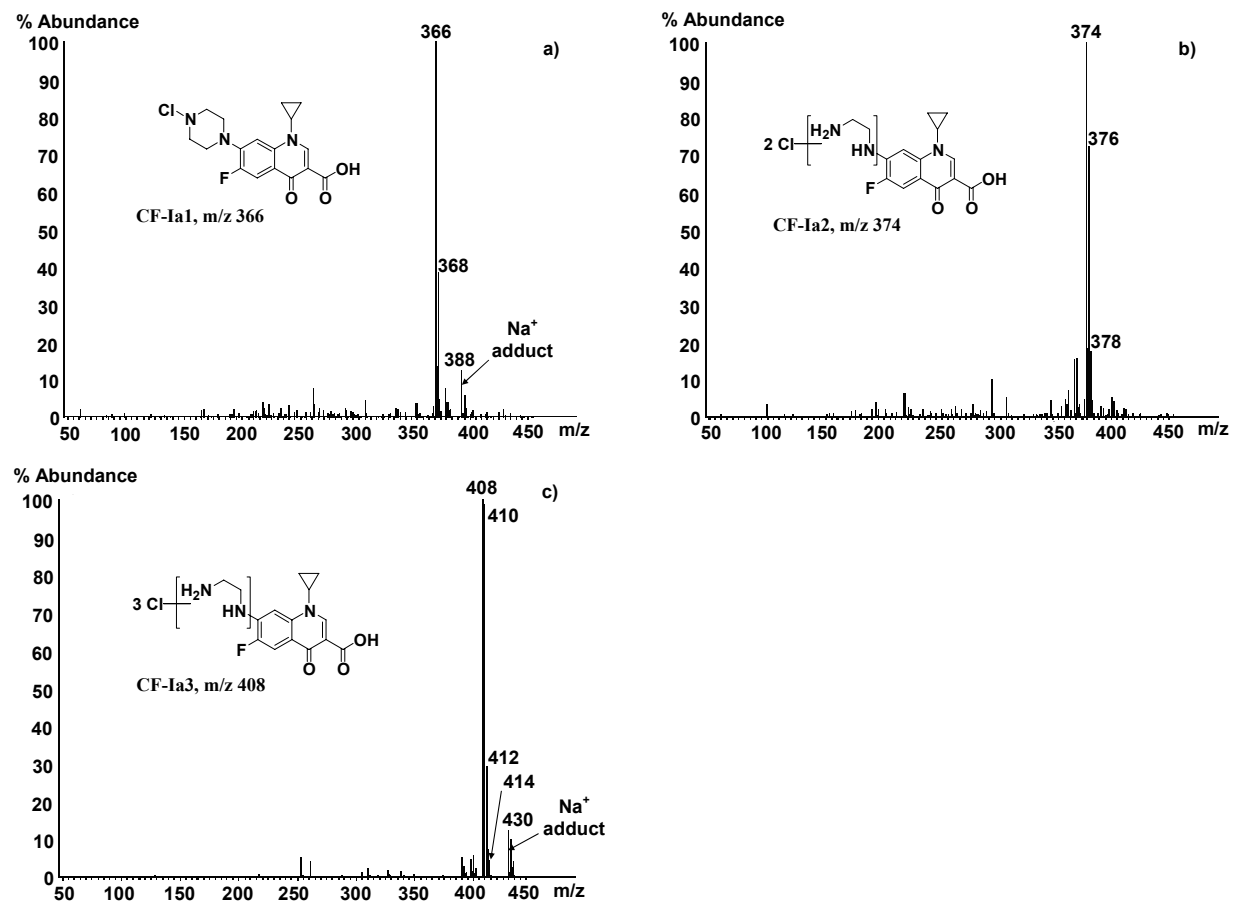

Figure S2. LC/MS-ESI ${ }^{+}$spectra for chloramine intermediates of the reaction between CF and FAC $\left(\mathrm{pH} 7\right.$, from unquenched reaction solutions containing $[\mathrm{CF}]_{0}=270 \mu \mathrm{M}$ and $[\mathrm{FAC}]_{0}=0.6$ to $1.2 \mathrm{mM}$ ):

(a) CF-Ia1, (b) CF-Ia2, (c) CF-Ia3 

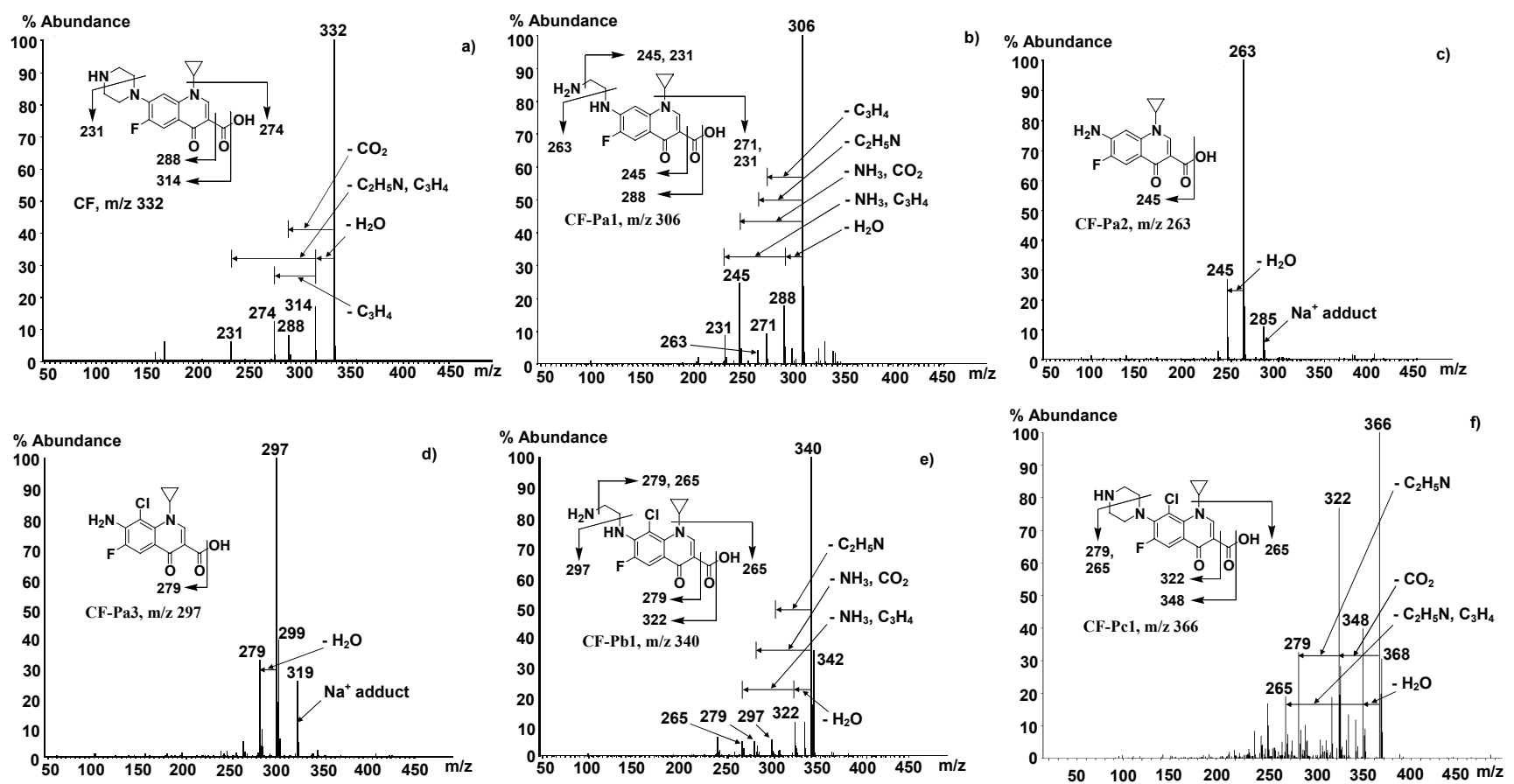

Figure S3. LC/MS-ESI ${ }^{+}$spectra for $\mathrm{CF}$ and identifiable products of the reactions between $\mathrm{FAC}$ and $\mathrm{CF}$ $\left(\mathrm{pH} 7\right.$, from quenched and unquenched reaction solutions containing $[\mathrm{CF}]_{0}=270 \mu \mathrm{M}$ and $[\mathrm{FAC}]_{0}=0.6$ to $1.2 \mathrm{mM}$ ): (a) CF, (b) CF-Pa1, (c) CF-Pa2, (d) CF-Pa3, (e) CF-Pb1 , (f) CF-Pc1. Fragment ions identified according to Golet et al. (9) and Volmer et al. (10)
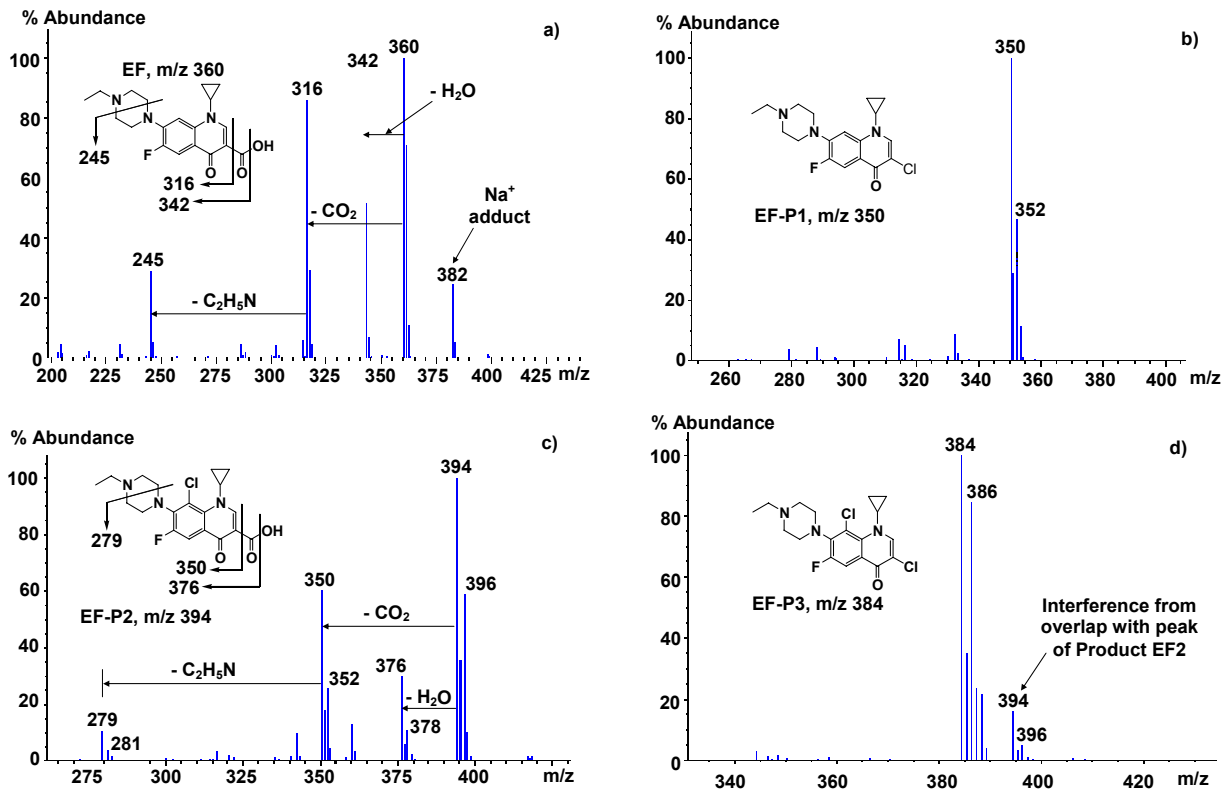

Figure S4. LC/MS-ESI ${ }^{+}$spectra for EF and identifiable products of the reactions between FAC and EF $\left(\mathrm{pH} \mathrm{7,} \mathrm{from} \mathrm{quenched} \mathrm{and} \mathrm{unquenched} \mathrm{reaction} \mathrm{solutions} \mathrm{containing}[\mathrm{EF}]_{0}=280 \mu \mathrm{M}\right.$ and $[\mathrm{FAC}]_{0}=$ 140 to $560 \mu \mathrm{M}$ ): (a) EF, (b) EF-P1, (c) EF-P2, (d) EF-P3. Fragment ions identified according to Volmer et al. (10) 


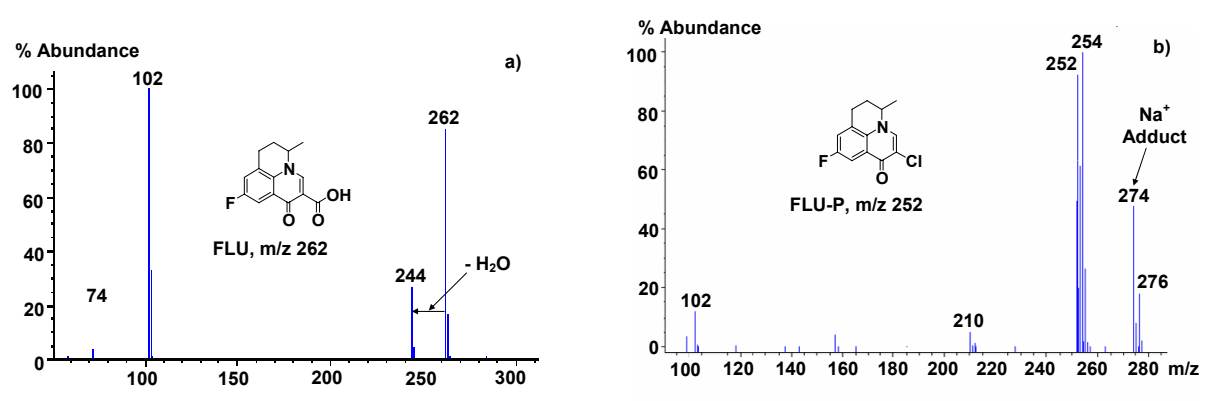

Figure S5. FLU and FLU-P ( $\mathrm{pH} 7$, from unquenched reaction solutions containing $[\mathrm{EF}]_{0}=280 \mu \mathrm{M}$, $[\mathrm{FLU}]_{0}=280 \mu \mathrm{M}$, and $[\mathrm{FAC}]_{0}=560 \mu \mathrm{M}$ ): (a) FLU, (b) FLU-P. Cl isotope ratio of the FLU-P sodium adduct peak is taken to represent the structure's true elemental composition. The reason for elevation of the isotopic ratio in the analyte's molecular ion peak is not known.

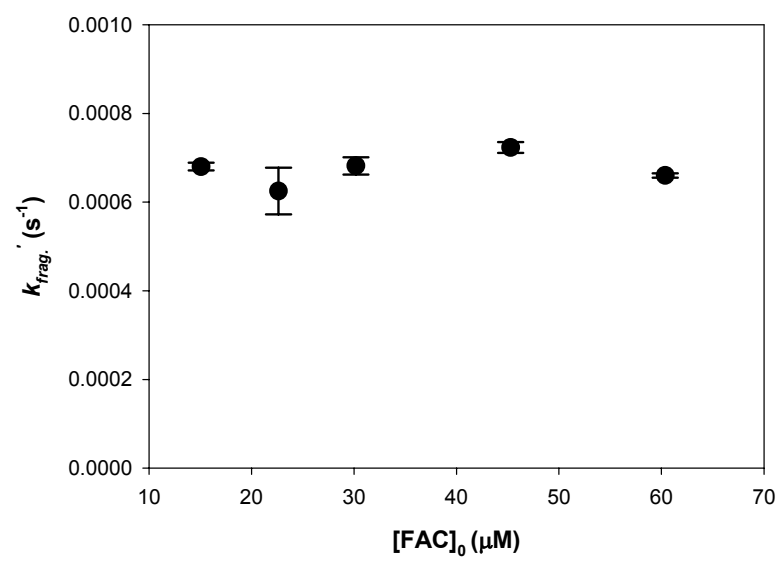

Figure S6. $[\mathrm{FAC}]_{0}$-independence of pseudo-first-order rate constant, $k_{\text {frag }}^{\prime}$, for CF-Ial decay to CFPal at $25^{\circ} \mathrm{C}$ and $\mathrm{pH} 7$ 


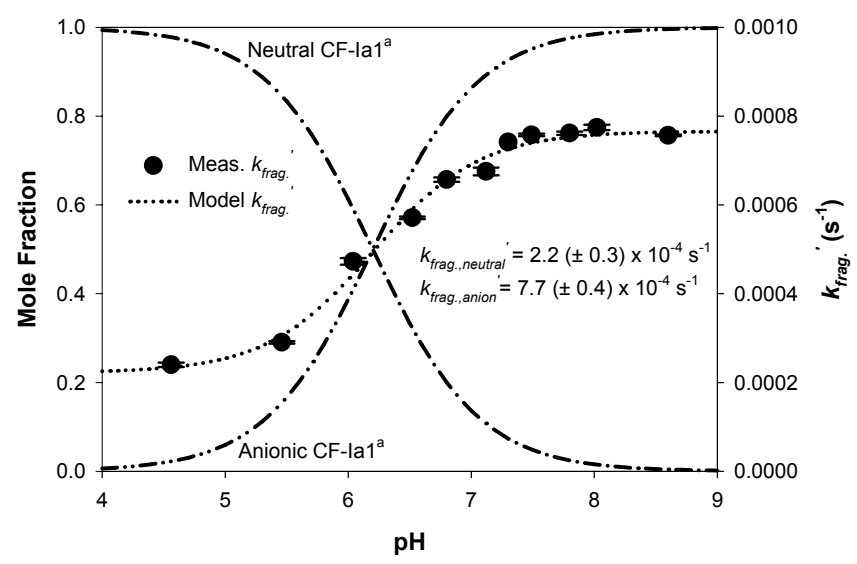

Figure S7. pH-dependence of pseudo-first-order rate constant, $k_{\text {frag }}^{\prime}$, for CF-Ia1 decay to CF-Pa1 at 25 ${ }^{\circ} \mathrm{C},[\mathrm{CF}]_{0}=1.4 \times 10^{-6} \mathrm{M}$, and $[\mathrm{FAC}]_{0}=1.5 \times 10^{-5} \mathrm{M}$. ${ }^{\text {a }}$ Measured data was modeled according to $\mathrm{p} K_{\mathrm{a} 1, \mathrm{CF}}=6.2$, which is assumed to approximate $\mathrm{p} K_{\mathrm{a}}$ for CF-Ia1, because the $\mathrm{N}(4)$ atom is not conjugated with the carboxyl group to which the former $\mathrm{p} K_{\mathrm{a}}$ value applies, as discussed in Text $\mathrm{S} 4$. 


\section{Literature Cited}

1. Dodd, M. C.; Huang, C.-H., Transformation of the antibacterial agent sulfamethoxazole in reactions with chlorine: kinetics, mechanisms, and pathways. Environ. Sci. Technol. 2004, 38, $5607-5615$.

2. Standard Methods for the Examination of Water and Wastewater; 20 ed.; APHA, AWWA, WPCF: Washington, 1998.

3. Muñoz, F.; von Sonntag, C., Determination of fast ozone reactions in aqueous solution by competition kinetics. J. Chem. Soc., Perkin Trans. 2 2000, 2, 661-664.

4. Gonzalez, A. C.; Olson, T. M.; Rebenne, L. M., Eds. Aqueous chlorination kinetics and mechanism of substituted dihydroxybenzenes; American Chemical Society: Washington, D.C., 1996; Vol. 649.

5. Rebenne, L. M.; Gonzalez, A. C.; Olson, T. M., Aqueous chlorination kinetics and mechanism of substituted dihydroxybenzenes. Environ. Sci. Technol. 1996, 30, 2235-2242.

6. Moore, H. E.; Garmendia, M. J.; Cooper, W. J., Kinetics of monochloramine oxidation of $N, N$ diethyl-p-phenylenediamine. Environ. Sci. Technol. 1984, 18, 348-353.

7. Qiang, Z.; Adams, C. D., Determination of monochloramine formation rate constants with stopped-flow spectrophotometry. Environ. Sci. Technol. 2004, 38, 1435-1444.

8. Tachikawa, M.; Sayama, C.; Saita, K.; Tezuka, M.; Sawamura, R., Effects of isocyanuric acid on the monochlorodimedone chlorinating rates with free chlorine and ammonia chloramine in water. Water Res. 2002, 36, 2547-2554.

9. Golet, E. M.; Alder, A. C.; Hartmann, A.; Ternes, T. A.; Giger, W., Trace determination of fluoroquinolone antibacterial agents in urban wastewater by solid-phase extraction and liquid chromatography with fluorescence detection. Anal. Chem. 2001, 73, 3632-3638. 
10. Volmer, D. A.; Mansoori, B.; Locke, S. J., Study of 4-quinolone antibiotics in biological samples by short-column liquid chromatography coupled with electrospray ionization tandem mass spectrometry. Anal. Chem. 1997, 69, 4143-4155. 